\title{
Central sleep apnoea in congenital muscular dystrophy
}

\author{
Meir H Kryger, Darlene G Steljes, Woon-Chee Yee, Eva Mate, Stephen A Smith, \\ Mark Mahowald
}

\begin{abstract}
Sleep-disordered breathing may occur in a wide variety of neuromuscular syndromes, and may present with diverse, often isolated, symptoms or findings such as excessive daytime sleepiness, pulmonary hypertension, congestive heart failure, morning headaches, or hypoxiainduced nocturnal seizures. The authors report two sisters with congenital muscular dystrophy in whom central sleep apnoea resulted in the isolated symptom of nocturnal seizures in one, and morning headaches in the other. Review of the literature reveals that sleep-disordered breathing may be common in neuromuscular disorders, and may often be present when clinical weakness is mild, and insufficient to result in diurnal respiratory dysfunction.
\end{abstract}

The spectrum of sleep-disordered breathing broadens as sleep studies are performed in more patients with neuromuscular disorders. We report the cases of two sisters diagnosed with congenital muscular dystrophy, whose major current symptoms are related to central sleep apnoea.

\section{Case 1}

This was a 25 year old female who was admitted to St Boniface General Hospital with a six week history of recurrent nocturnal grand mal seizures and "awakening from sleep not being able to breathe".

She was born a floppy infant, following a normal pregnancy in which foetal movements were distinctly reduced. The weakness was generally proximal and not severe enough to limit general activities of living. The weakness remained stable until one year before admission, when she developed difficulty climbing stairs and doing her hair. An elder sister, aged 34 , has a similar though milder form of the disorder (case 2). Two other sisters and a brother, as well as both parents were unaffected.

Examination showed a female in no distress in spite of grossly abnormal blood gases. She had an elongated face with a myopathic facies, kyphoscoliosis of the spine and a high-arched palate. Her musculature was generally thin, with symmetrical weakness $[4+/ 5$ (MRC scale)] of proximal and distal muscles. The remainder of the neurological examination was normal. She had excessive daytime sleepiness and was difficult to arouse from sleep.
While awake she had frequent vivid visual hallucinations. There was about a $50 \%$ reduction in lung volumes associated with the kyphoscoliosis. Peak inspiratory pressure was $-40 \mathrm{cmH}_{2} \mathrm{O}$.

In the ICU, on nasal oxygen, arterial blood gases were: $\mathrm{pH} 7 \cdot 10-7 \cdot 32 ; \mathrm{PaCO}_{2} \quad 80$ $122 \mathrm{mmHg} ; \mathrm{PaO}_{2} 45-75 \mathrm{mmHg}$. She became apnoeic during sleep and had to be vigorously stimulated to resume respiration. Polysomnography revealed sleep-onset REM sleep with central apnoeas lasting $45-60 \mathrm{~s}$. The last apnoea continued for over a minute without resuming breathing with $\mathrm{SaO}_{2}$ falling below $30 \%$. Respiration resumed only with vigorous stimulation. Mechanical ventilation via a nasal mask (but not nasal CPAP) was very effective. She then had long periods of REM followed by NREM sleep. There was one period lasting several minutes when the EEG demonstrated slow waves characteristic of NREM sleep, and simultaneously the EOG, rapid eye movements (fig).

Despite acceptable peak inspiratory pressures, both hypoxic and hypercapnic drives to breathe were virtually absent. Auditory brainstem evoked potentials showed mild peripheral delay in the portion of the right ear. Somatosensory evoked potentials showed borderline slowing in central conduction from the lower limb. Nerve conduction studies were normal. EMG demonstrated a myopathic pattern. The creatinine phosphokinase level was mildly elevated (196 $\mu / 1$-normal 28-110 $\mu / 1)$. A sural nerve biopsy did not show significant abnormalities. CT and MRI scans of the brain were both normal.

The patient was sent home with a PLV 100 ventilator and a nasal mask. There was dramatic improvement in her daytime performance and she has returned to work. A repeat sleep study on the ventilator a month later showed no sleep-disordered breathing and normal sleep architecture. Awake arterial blood gases were normal six months later. Three years after discharge she continues to do well on nocturnal ventilation.

\section{Case 2}

This 33 year old sister of case 1 has a similar neuromuscular disorder but with less severe generalised weakness, and nocturnal headaches. She was also a floppy baby and has mild kyphoscoliosis. She has mild facial and tongue paresis, prominent neck flexor weakness with mild to moderate weakness of her shoulder and pelvic girdles. Her deep tendon reflexes were present but reduced throughout. EMG 
Figure Rapid eye movements ( $R E M S$ ) during a period of slow wave sleep. C4/A1 and $C 3 / A 2$ are the $E E G$ derivations. EOG is the electro-occulogram. This type of dissociated state is possibly due to previous REM deprivation.

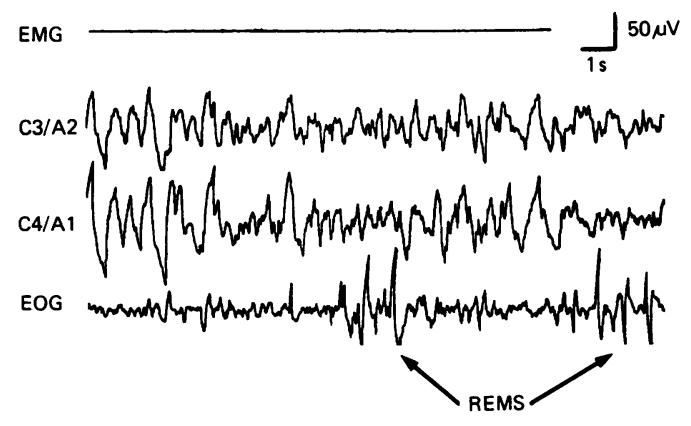

and nerve conduction studies were similar to case 1 .

A left biceps muscle biopsy showed no degenerating or regenerating fibres. Internal nuclei and fibre splitting were rare. No inclusions were seen in any stain. Some of the type I fibres showed mild "moth-eaten" architectural changes on the DPNH, LDH and SDH stains. Electron microscope examination showed no abnormalities. The mitochondria were normal and no abnormal inclusions were seen. The impression was a mild, non-specific change consistent with a myopathy.

Polysomnography showed central apnoeic episodes only during REM; during $59 \mathrm{~min}$ utes of REM there were 66 apnoeic episodes (mean $29 \mathrm{~s}$ duration). $\mathrm{SaO}_{2}$ dropped to a mean of $82 \%$ (lowest $74 \%$ ) during the episodes. The patient opted for no treatment at this time.

\section{Discussion}

Both sisters have a similar neuromuscular disorder presenting with hypotonic weakness at birth, non-progressive generalised weakness, skeletal deformities and EMG changes of a myopathy. No other family member appeared to be affected. Muscle biopsy of one of the sisters showed non-specific myopathic changes, and certainly no unique hallmark changes of one of the congenital myopathies, such as nemaline rods, central cores, central nuclei or prominent type I hypertrophy. These findings have led us to the diagnosis of congenital muscular dystrophy.

The term congenital muscular dystrophy (CMD) denotes a group of genetically transmitted degenerative disorders of muscle defined by clinical features of weakness from birth and pathological features of a myopathy characterised by a lack of specific or unique histochemical or electron microscopic features. CMD encompasses a range of disorders which have been categorised and discussed by Banker ${ }^{1}$ and others. ${ }^{2-5}$ Our cases are considered to fall into a benign subcategory. Both clinically and radiologically, the disorder in these patients has shown no features of central nervous system involvement.

Case 1 presented with nocturnal seizures (possibly hypoxia induced) and hypnagogic hallucinations. The most important findings in our index case are blunted chemical drives to breath, hypoventilation while awake, and very severe apnoea during sleep. These abnor- malities were far out of proportion to the somatic and respiratory muscle weakness.

Our first patient had evidence of a moderately severe restrictive lung disorder, kyphoscoliosis and a reduction in lung diffusing capacity $\left(D_{L} C O\right)$. Her sister also had a restrictive lung disorder. The reduction in our index case of maximum inspiratory pressure has been previously described in virtually all the myopathic disorders which may involve the respiratory muscles. The reduction, however, was not felt to be sufficient to explain the severe respiratory failure during wakefulness and sleep. A patient able to generate $-40 \mathrm{cmH}_{2} \mathrm{O}$ pressure should not develop respiratory failure. In case 2 , the isolated sleep complaint was nocturnal headache.

\section{Control of breathing}

When examining the spectrum of disorders which may cause weakness of the diaphragm, there is not a linear relationship between respiratory muscle weakness and chemical drives to breathe. Chemical control of breathing may be normal in patients with myopathies. ${ }^{6}$ In myotonic dystrophy the chemical drives to breathe may be abnormal ${ }^{78}$ as assessed by ventilation, but may be normal as assessed by mouth occlusion pressure suggesting that chemosensitivity of the respiratory centres is normal, but the ventilatory response is blunted by the abnormal respiratory mechanics. ${ }^{8}$ Abnormalities in chemical control of breathing out of proportion to weakness have been found in myotonic dystrophy, ${ }^{9}$ oculocraniosomatic neuromuscular disease ${ }^{10}$ and nemaline myopathy. ${ }^{11}$ The reason for the blunted drive in these disorders is unknown but suggests that there is a disorder not only of muscle, but also of central nervous system function. Alveolar hypoventilation has been described in myotonic dystrophy ${ }^{9}$ and acid maltase deficiency. ${ }^{12}$

\section{Sleep breathing disorders}

A variety of sleep-related respiratory dysfunctions have been reported in isolated series of patients with an assortment of neuromuscular disorders. ${ }^{913-18}$ Whenever breathing during sleep has been assessed in neuromuscular disorders, when abnormalities were present, they were most severe in REM sleep. There are several possible explanations for this. First, chemical control of breathing (hypoxic and hypercapnic) is the most blunted in REM in normal subjects. ${ }^{19}$ Second, there occurs throughout REM a generalised loss of muscle tone which may result in hypoventilation. Third, during the phasic manifestation of REM it is likely that hypoventilation occurs, as has been described in lung diseases. ${ }^{20} 21$

Muscle weakness per se is insufficient to explain sleep-disordered breathing in such patients, since ventilation and clinical motor strength may be adequate during wakefulness. Thus mechanical ventilation may only be needed during sleep. In some patients with awake hypoventilation, as in our patient, effective nocturnal ventilation may result in disappearance of daytime hypoventilation. ${ }^{2211}$ The reasons for this are unclear but may reflect the 
blunting of respiratory drive by sleep fragmentation.

Our index patient had several abnormalities in sleep structure. First was the sleep-onset REM sleep which occurred when she was studied without mechanical ventilation. Second she apparently had dissociations of sleep/awake states, causing vivid visual hypnagogic hallucinations. ${ }^{23} 24$ In addition, upon institution of nasal mechanical ventilation, she demonstrated simultaneously slow wave NREM sleep on EEG and rapid eye movements (on EOG). This combination suggests a dissociation of the normal sleep states. This unusual EEG sleep pattern deserves comment. It is clear that the component characteristics of wakefulness, REM and NREM may occur in incomplete form, oscillate rapidly, or occur simultaneously. The coincident occurrence of multiple state-determining characteristics (EEG evidence of slow-wave sleep with rapid eye movements characteristic of REM sleep) has been termed "status dissociatus". ${ }^{25}$ It may be induced by medication, be associated with withdrawal states or neurological disorders, and in this case, may be a manifestation of previous REM sleep deprivation.

The mechanism of hypoxia-induced seizures is of note, as the "seizures" may not be seizures in the conventional sense of the term (uncontrolled cortical neuronal discharges), but may represent the release of primary brainstem phenomena (such as intermittent decerebration) as a result of absence of the usually present hemispheric (cortical) inhibitory influences. $^{2627}$

\section{Therapeutic implications}

It is clear that patients with neuromuscular disorders may experience severe state-dependent respiratory dysfunction ${ }^{1622}$ necessitating sleep-period mechanical ventilation. ${ }^{1822}$ In case 1 , mechanical ventilation only during sleep has abolished nocturnal seizures, hypnagogic hallucinations, excessive daytime sleepiness and daytime hypoventilation. This mode of therapy has been employed previously in patients with neuromuscular disorders. ${ }^{28} 29$

Several important common threads emerge which may be helpful in clinical assessment. In patients with neuromuscular disorders, daytime sleepiness, disturbed sleep, morning headaches, or nocturnal seizures ${ }^{1822}$ may be markers of abnormal respiration during sleep. Even in the absence of these symptoms, severe sleep-breathing abnormalities may still occur. ${ }^{1516}$ The symptoms in a patient with neuromuscular disease should suggest statedependent respiratory dysfunction, which may have important and dramatic therapeutic implications. There may be a marked discrepancy between respiratory function while awake and during sleep.
1 Banker BQ. Congenital muscular dystrophy. In: Engel AE, Banker BQ, eds. Myology. New York: McGraw-Hill, 1986:1367-82

2 Zellweger H, Afifi A, McCormick WF. Mergner W. Benign congenital muscular dystrophy: a special form of congenital hypotonia. Clin Pediatr (Bologna) 1967;6:655.

3 Nonaka I, Chou SM. Congenital muscular dystrophy. In: Vinken PJ, Bruyn GW, eds. Handbook of clinical neurology 1979;42:27-50.

4 Batten FE. Myopathy. Simple atrophic type. Proc $R$ Soc Med (Neurol) 1915;8:69.

5 Egger J, Kendall BE, Erdohazi M, Lake BD, Wilson J, Brett $\mathrm{EM}$. Involvement of the central nervous system in con1983;25:32-42.

6 Begin R, Bureau MA, Lupien L, et al. Control of breathing in Duchenne's muscular dystrophy. Am J Med 1980; 69:227-33.

7 Serisier DE, Mastaglia FL, Gibson GJ. Respiratory muscle function and ventilatory control $I$ in patients with motor neurone diagnosis II in patients with myotonic dystrophy. Q J Med 1982;51(202):205-26.

8 Begin R, Bureau MA, Lupien L, et al. Control and meditation of respiration in Steinert's myotonic dystrophy. Am Rev Respir Dis 1980;121:281-9.

9 Kilburn KH, Eagon JT, Stekor HO, et al. Cardiopulmonary insufficiency in myotonic and progressive muscular dystrophy. N Engl J Med 1959;268:1089-96.

10 Weng TR, Schultz GE, Chang HC, Nigro MA. Pulmonary function and ventilatory response to chemical stimuli in familial myopathy. Chest 1985;88(4):488-95.

11 Maayan C, Springer C, Armon Y, Bar-Yishay E, Shapira Y, Godfrey $S$. Nemaline myopathy as a cause of sleep hypoventilation. Pediatrics 1986;77(3):390-5.

12 Engel AG. Acid Maltase deficiency in adults: studies in four cases of a syndrome which may mimic muscular dystrophy or other myopathies. Brain 1970;93:599-616.

13 Cumminskey J, Lynne-Davies P, Guilleminault C. Sleep study and respiratory function in myotonic dystrophy. In: Guilleminault C, and Dement WC, eds. Sleep apnoea syndromes. New York: Alan R Liss, 1978:295-308.

14 Coccagna G. Mantovani M, Parchi C, Mironi F, Lugaresi E. Alveolar hypoventilation and hypersomnia in myotonic dystrophy. J Neurol Neurosurg Psychiatry 1975;38: 977-84.

15 Smith PEM, Calverley PMA, Edwards RHT. Hypoxemia during sleep in Duchenne Muscular Dystrophy. Am Rev Respir Dis 1988;137:884-8.

16 Wilson DO, Sanders MH, Dauber JH. Abnormal ventilatory chemosensitivity and congenital myopathy. Arch Intern Med 1987;147:1773-7.

17 Bellamy D, Newsom-Davis JM, Mickey BP, et al. A case of primary alveolar hypoventilation associated with mild

18 Chan CK, Mohsenin V, Loke J, Virgulto J, Sipski L, Ferranti R. Diaphragmatic dysfunction in J, Sipski L, Ferranti $R$. Diaphragmatic dysfunction in siblings with hereditary motor and sensory neuropathy
Marie-Tooth disease). Chest 1987;91(4):567-70.

19 Sullivan CE, Issa FG. CPAP therapy in sleep apnea. In: Kryger MH, Roth T, Dement WC, eds. Principles and practice of sleep medicine, Philadelphia: WB Saunders, 1989 .

20 George CF, West P, Kryger MH. Oxygenation and breathing pattern during phasic and tonic REM in patients with COPD. Sleep 1987;10(3):234-43.

21 Orem JM. Respiratory neuronal activity in sleep. In: Edelman NH, Santiago TV, eds. Breathing disorders of sleep, Vol 5. New York: Churchill Livingstone, 1986 $19-44$.

22 Riley DJ, Santiago RV, Daniele RP, et al. Blunted respiratory drive in congenital myopathy. Am J Med 1977; 63:459-66.

23 Liddon SC. Sleep paralysis and hypnagogic hallucinations; their relationship to the nightmare. Arch Gen Psychiatry 1967;17:88-96.

$24 \mathrm{McDonald} C$. A clinical study of hypnagogic hallucinations. Br J Psychiatry 1971;118:543-7.

25 Mahowald MW, Schenck CH. Status dissociatus-a perspective on states of being. Sleep 1991;4:69-79.

26 McNamara JO. Human hypoxia and seizures: effects and interactions. Adv Neurol 1979;26:137-43.

27 Gastaut H, Fischer-Williams M. Electro-encephalographic study of syncope; its differentiation from epilepsy. Lancet 1957;i:1018-25.

28 Kerby GR, Mayer LS, Pingleton SK. Nocturnal positive pressure ventilation via nasal mask. Am Rev Respir Dis 1987;135:738-40.

29 Ellis ER, Bye PTP, Bruderer JW, Sullivan CE. Treatment of respiratory failure during sleep in patients with neuromuscular disease. Positive pressure ventilation through a nose mask. Am Rev Respir Dis 1987;135:148-52. 